\title{
Libraries in the digital world: Library projects in the European Commission's Information Society Technologies (IST) Programme
}

\section{Rosalind Johnson}

\section{The author}

Rosalind Johnson is a freelance editor, writer and information specialist. She acts as European Consultant for CILIP: the Chartered Institute of Library and Information Professionals.

\section{Introduction}

Traditional libraries could be inward looking; dedicated to their users, but unaware of the broader picture of library activity. While some co-operation did exist, it took the new computing and telecommunications technologies that were developed from the 1970s onwards to facilitate the widespread sharing of resources beyond a national level. The European Commission (EC), aware of the need to share library resources across Europe to the benefit of libraries and their users, funded research into the use of new technology to facilitate this in libraries under the Telematics for Libraries Programme (1990 to 1998). This work of this programme continued under the Information Society Technologies (IST) Programme.

\section{The IST Programme in European research}

The IST Programme was part of the much wider Fifth Framework Programme (FP5) on Research and Technological Development (1998 to 2002).

Framework Programmes support multinational projects and other research activities to provide solutions to major socio-economic challenges such as increasing Europe's industrial competitiveness, job creation and improving the quality of life for European citizens. FP5 had a total budget of 14.96 billion euro. The EC sees the process of innovation as crucial to ensure the output of EU research is translated into tangible benefits for all. In the area of cultural heritage (libraries, museums and archives) innovation can be a challenge, as not all projects are immediately attractive to commercial interests once EC funding has ceased.

The IST Programme was one of four 'Thematic Programmes' supported under the overall FP5 umbrella. These were:

- Quality of Life and Management of Living Resources

- Promoting a User-Friendly Information Society (Information Society Technologies)

- Competitive and Sustainable Growth (GROWTH)

- Energy, Environment and Sustainable Development (EESD) 
The total budget for the IST Programme within FP5 was 3.6 billion euro. This was divided within the IST Programme, principally among various 'Key Actions'. Libraries, museums and archives were mainly involved in Key Action 3: Multimedia Content and Tools. The main objective of this action was to improve information products and services in support of linguistic and cultural diversity and to enhance education and training systems for lifelong learning.

\section{Digital Heritage and Cultural Content in the IST Programme}

Digital heritage and cultural content was one of the five main areas for research and technological development under Key Action 3. Work was aimed at expanding the contribution of libraries, museums and archives ('memory institutions' in EC jargon) to the emerging culture economy, including economic, scientific and technological development. The EC identified three research priorities:

- Ensuring integrated access to collections and materials held in libraries, museums and archives

- Improving the operational efficiency of large-scale content holdings by means of powerful interfacing and management techniques

- Preserving and accessing multimedia content of various types, including electronic materials and surrogates of physical objects

Since 1999 around 100 projects and other initiatives have received funding in the area of digital heritage and cultural content. These projects are building on the results of earlier research programmes, as well as addressing future issues concerning technical approaches and applications for networked information services and cultural heritage institutions.

\section{Digital Heritage and Cultural Content activities}

Pan-European research projects are the activities often identified with this IST Programme, including the area of digital heritage and cultural content. In addition to research projects the sector has funded other activities, including the creation of a number of European-level networks. Furthermore, in 2000 a call for smaller-scale take-up actions was issued. These take-up activities were designed to launch trial actions across Europe to encourage take-up of results and stimulate the implementation of innovative new products and services in the cultural heritage sector.

Together, these activities cover many themes within the common area of digital heritage and cultural content. Among the topics covered are licensing information, film archives, digital libraries, metadata, public libraries, academic Internet information sources, national libraries, and digitisation.

What are the common challenges which these projects and actions seek to address? What are the problems facing libraries, together with museums and archives, which the European Commission aims to solve with these collaborative European actions? How can the user be provided with seamless, high value, interactive services based on their 
distributed resources? These questions can be answered by reference to examples from the wide body of research.

Physical objects are increasingly made available by digital means. For example, scanning paper documents into an electronic database, uploading to an intranet, or mounting on a web site. This may preserve just the information (text, graphs, graphics) of the original document, but may include a representation of the actual physical document itself.

These issues are being addressed by research work in project Memorial, which aims to provide a new technical approach based on Optical Character Recognition (OCR) techniques, in order to deal with a wide variety of paper documents in libraries, archives, public record offices and museums. Memorial intends to create a 'digital document workbench' for the preservation of personal records of Holocaust survivors. The project aims both to improve access to this material for the general public, as well as providing a dedicated data resource for special interest groups, notably relatives of victims and survivors researching their family history. The challenges faced by Memorial include the poor state of preservation of many surviving documents, and the need to make available additional data included on many documents, such has hand-written comments and information provided by rubber stamps. Memorial also seeks to address problems arising from variations of personal and place names in various European languages.

The preservation of, and access to, original copy in virtual form is addressed in a number of other projects. These include METAe, whose aims include the development of an omnifont OCR-engine specialising in processing old European typefaces of the 19th century. In this area also, project Echo has been developing a reusable software architecture for digital film archives which will facilitate web-based access to documentary film collections of great historical value. The system aims also to improve the productivity and effectiveness of the archives and ensure their usability for the long term.

Several trial actions addressed virtual representation of actual objects. For example, Books2U! sought to adopt a new approach to the inter-library loan of old and rare books, based on the digitisation of historically significant documents and providing access via the web.

The preservation of hard copy raises one set of issues. As more objects are created by digital means, without any physical equivalent, other issues are being raised. Digital objects include electronic documents, but the digital creation of objects also includes web pages, music and art work. How does one facilitate access and use?

To facilitate access and use the creation and maintenance of effective standards is crucial. Developments in standardisation such as MPEG-4 and MPEG-7 are of significance for digital heritage. Projects examining metadata are vital to this area of research. Metadata embedding will enhance multimedia standards, leading to improved search encoding and retrieval facilities. 
An example of a project addressing issues including metadata and standards is Covax. Covax is drawing up a global search and retrieval solution for all types of archive, library and museum collections based on the application of SGML/XML. It plans to combine document descriptions and digitised surrogates to build a global system for search and retrieval. Virtual access will enable the primary documents to be accessed regardless of their physical location. The project has four basic aims: dissemination of European cultural heritage, facilitating access for European citizens to primary sources of intellectual, cultural and scientific heritage stored in archives, libraries and museums; exploitation over the Internet of existing cultural infrastructures; the use of standards in the field of information structure and retrieval and interoperability between systems (interoperable access to distributed resources) based on the complementary capabilities of each partner.

A concerted effort by the European Commission to address the complex area of standards is demonstrated by Diffuse. The stated objective of the Diffuse project is to provide a single, value-added, entry point to up-to-date reference and guidance information on available and emerging standards and specifications that facilitate the electronic exchange of information. Its services include regular updates, conferences, and a list of standards.

Many projects have been obliged to include considerations of data protection and copyright restrictions in their work programmes. Licensing is a related issue, and project Celip builds on earlier research to address licensing concerns, specifically for Central and Eastern Europe.

How is cultural content to be used by European citizens? The EC is increasingly concerned to address issues of use, and user involvement in its research projects. In the area of academic information, project Renardus has been exploring the possibilities of collaborative models between national services on a European scale to provide integrated access to national networks of subject gateways and metadata repositories for users in higher education. The project has also explored issues of standardisation and discussed new business models for this type of service.

Other projects involve very different groups of user. Project Chimer will involve children, harnessing their natural enthusiasm to develop new approaches to using technology to document items of cultural interest in their communities. Project Coine is creating a user-friendly web interface to enable ordinary citizens, both individuals and small groups, to record and share their personal and community heritage.

To support research activities, the EC has funded a number of networks in the area of digital heritage and cultural content. These include Pulman, a network to provide services to public libraries, and Cultivate, which provides information on the IST programme to potential participants.

The Erpanet network seeks to establish an electronic resource preservation and access network of excellence. It will bring together not only libraries, museums and archives, but also ICT organisations, the creative industries and government institutions. These 
various groups will collaborate on solutions to the challenges faced by the widespread use of digital technologies. Erpanet has identified these as including a lack of awareness, a fragmentation of knowledge and skills among the stakeholder communities, lack of effective forward planning and future thinking, and the need to focus on core research areas.

Delos, a long-standing network, is a network of excellence on digital libraries. It provides an open forum within which to debate and set an international research agenda and stimulates exchange of know-how and best practices. The Delos consortium states that it constitutes a reference point for all digital library projects funded by the IST Programme, stimulating the exchange of experiences and knowledge. However, its activities are open to all the Digital Libraries research world, with the aim of establishing close contacts with other relevant communities, including archives and electronic publishing enterprises. The Delos network has held a number of open seminars and conferences, and supports several forums investigating various digital library issues.

\section{The future}

The future of digital heritage and cultural content research funding within the EC is directly affected by proposals under the new Sixth Framework Programme (FP6) which will run from 2002 to 2006 . An information society technologies programme is included in FP6, and calls for the first project proposals are expected in late 2002 or early 2003.

Work has been ongoing in the EC to identify areas of key importance in the sector. Within the area of digital heritage and cultural content, digitisation has been identified as a key priority. Work has been ongoing in the area of co-operation between EU member states on digitisation issues through the Lund Action Plan. This work links with objectives in the EC's eEurope initiative for the information society, and to FP6 objectives. National representatives act as a steering group for this initiative, and produced their Terms of Reference during their meeting in Alicante in May 2002. Further support for the Lund Action Plan principles comes via the Minerva network. Minerva brings together government ministries and other national bodies to provide a collaborative framework for the Lund Action Plan and its working groups within the EU member states.

Future concerns for digital heritage were identified in the EC funded report, 'Technological Landscapes for Tomorrow's Digital Economy' (2201). This study covered several areas of interest to the sector, including national policies, national initiatives, organisational change, exploitation of results, and information and computing technology. It made a series of recommendations, and in particular provided a roadmap of how cultural heritage technologies might be expected to develop in the period until 2006. Drawing on this report, the DigiCULT support measure is establishing a regular technology watch for cultural and scientific heritage during the period March 2002 to August 2004.

However, projects in FP6 are likely to be far larger in scale than in FP5, and the proposed 'networks of excellence' will be similarly substantial. This has caused concern to the 
cultural heritage area, which tends to be involved in relatively small projects. However, the networks of excellence may be able to issue their own calls for proposals, which could mean opportunities for the cultural heritage sector. Additionally, the EC is putting extra emphasis on 'ambient technology', or transparent user-centred solutions, including research into mobile applications, to provide inclusive access for users. This could mean opportunities for libraries, with their historic close relationship to their users, to collaborate with commercial technical companies on research into the applications of cultural heritage content and technology.

\section{References}

Fifth Framework Programme: http://www.cordis.lu/fp5/home.html

IST Programme: http://www.cordis.lu/ist/

Digital Heritage and Cultural Content in the IST Programme:

http://www.cordis.lu/ist/ka3/digicult/

Links to projects mentioned in the text: see links at: http:/www.cordis.lu/ist/ka3/digicult/

DigiCULT: http://www.digicult.info/pages/index.html 